\title{
STUDY OF INCIDENCE OF OSTEOPOROSIS INDUCED FRACTURES IN THE ELDERLY AFTER ONCE YEARLY ZOLEDRONIC ACID INJECTION
}

\author{
Orthopaedics \\ Dr. Raveendra \\ Babu. \\ Rayalapeta. \\ Veerappa*

\section{Dr. Achyuth Babu. Rayalapeta Bodan} \\ $\&$ Research Centre, Chittoor, AP. *Corresponding Author
}

Associate Professor, Department Of Orthopaedics, Apollo Institute Of Medical Sciences

\begin{abstract}
Introduction: In developing countries like India, the various socio-economic factors like anaemia, hypo proteinemia, early menopause, hysterectomy at younger age and loss of teeth at early age are leading causes of osteoporosis. The treatment for all the above problems at community level is difficult job. We advocated IV injections of Zoledronic acid once in a year which is feasible and possible way of preventing the progression of osteoporosis. This is evidenced by decrease in incidence of new fractures in our patients.

Patients And Methods: We studied the efficacy of once yearly IV injection of Zoledronic acid -ZOLE to prevent osteoporotic fractures in the 130 elderly patients and compared the incidence of fractures in the placebo group of 150 patients who were not received the ZOLE injection. The age group ranges from 50 to 70 years who attended OP unit of our Orthopaedic department from January 2018 to December 2019 ( 2 years). These 280 patients presented with common fractures like fracture neck of femur-110, vertebral fractures-85, proximal tibial fractures-15, proximal humoral fractures-15 and distal radial fractures-55. IV Zoledronic acid was given to 130 patients in addition to fracture treatment. The remaining 150 patients who were not willing for IV injections for various reasons were included in the placebo group of our study.

Results: We assessed the incidence of new fractures in both the groups patients, ZOLE group who received Zoledronic injection and placebo group who were not received injection for 2 years period. The incidence of new fractures was significantly diminished in ZOLE group compared to placebo group. We observed the incidence of all cumulative fractures were 30 fractures (24\%) in the ZOLE group and in the placebo group the incidence was 110 fractures (76\%). Bone mineral density (BMD) of Lumbar spine, femoral neck, proximal humerus and distal radius were done for all the patients at the time of starting of the study and at 2 years follow-up. We observed increased BMD in the ZOLE group. There were no adverse effects like osteonecrosis of jaw and others in our study.

Conclusion: In rural areas of developing countries, with poor socioeconomic status, early osteoporosis is prevalent and causing the major fractures after trivial injury. Once yearly administration of Zoledronic acid $5 \mathrm{mg}$ IV is safe and effective way of preventing the incidence of Fractures and subsequent morbidity and mortality.
\end{abstract}

\section{KEYWORDS}

Osteoporosis, Zoledronic acid, Bone Mineral Density.

\section{INTRODUCTION:}

Zoledronic acid $[\mathrm{ZOL}]$ is a bisphosphonate that contains an imidazole ring in a side chain. We are giving once yearly intra- venous infusion and noticed the increased BMD and decrease in incidence of osteoporotic fractures. The ZOL is mediated by a potent inhibitory effect on bone resorption ${ }^{1}$. This preventive treatment is approved in various countries for post-menopausal osteoporosis, steroid induced osteoporosis $^{3}$ and male osteoporosis ${ }^{4}$. The dosage is same for all the above indications that is once yearly intravenous infusion of $5 \mathrm{mg}$ of ZOL. In the HORIZON-PET ${ }^{2}$ (Health Out-comes and Reduced Incidence with Zoledronic acid Once yearly- Pivotal Fracture Trial) clinical study, 7736 patients with post-menopausal osteoporosis received IV injections of $\mathrm{ZOL}$ at dose of $5 \mathrm{mg}$. After 3 years of treatment there was significant reduction of vertebral fractures, reduced incidence of hip fractures, distal radial fractures and increase in bone mineral density ${ }^{5}$. We conducted a 2 year randomised placebo controlled comparative study to determine the efficacy, safety and prevention of primary osteoporosis in Indian patients.

\section{PATIENTS AND METHODS:}

This study was conducted in our teaching hospital attached to medical college situated in backward and low socio-economic area of Chittoor Andhra Pradesh. We prepared a proforma of patients' demography like age, sex, height, weight, body mass index $\mathrm{kg} / \mathrm{m}^{2}$, vitamin-D levels and BMD. The 280 elderly patients attended to our out-patient clinic with various fractures for last 2 years were included in our study.

The patients with history of bisphosphonates in-take with-in two years prior to the study, severe complications of heart, liver and kidney were excluded from the study. In the ZOLE group 130 patients were included, of which fracture neck of femur were 45 cases, vertebral fractures were 35 , proximal tibial fractures were 15, proximal humoral fractures were 10 and distal radial fractures were 25. All these ZOLE group patients were given IV infusion of $5 \mathrm{mg}$ Zoledronic acid over 15 minutes apart from the management of fractures. The placebo group of 150 patients, whom the ZOLE injections were not given as most of them were not willing for IV infusions and fear of IV medicines. Of these placebo group of 150 patients, the fracture neck of femur were 65 cases, vertebral fractures were 50, proximal humoral fractures were 5 and distal radial fractures were 30 . Informed consent was taken from all the patients. Both the groups of patients were given daily supplementary doses of $610 \mathrm{mg}$ calcium, $400 \mathrm{IU}$ vitamin -D and 30mg magnesium. We have not noticed adverse events like fever, flu like illness, malaise, headache and arthralgia after ZOLE IV infusion. The long term adverse events like osteo-necrosis of jaw, ECG changes were not noticed in our study. There were no mortalities in both ZOL and placebo groups.

The patients were clinically examined regularly once in a month. In doubtful cases X-rays of the D-L spine and pelvis including both hip joints were studied. The end point for our study was either occurrence of new fractures or end of two years fallow-up. Bone mineral density was assessed with the Dual Energy X-Ray Absorpiometry(DEXA).

\section{RESULTS:}

Total 280 patients were fallowed up in our study. In the ZOL group of 130 patients, the incidence of new fractures were $30(24 \%)$. The females were $20(67 \%)$ and males were $10(33 \%)$. The new fractures incidence in the placebo group of 150 patients was 110 fractures $(73 \%)$ ,of these 80 fractures $(73 \%)$ were females and 30 cases were males $(27 \%)$. The two year incidence new fractures was 110 in the placebo group compared to 30 in the ZOL group indicates that the patients who received IV infusion of ZOL were definitely benefited and had lesser incidence of new fractures. The percentage of change in BMD in ZOL group is higher compared to placebo group ${ }^{7,8}$ as shown in the table no. 1.

\begin{tabular}{|l|l|l|l|l|}
\hline $\begin{array}{l}\text { Average Measurement Of BMD In The Lumbar Spine, } \\
\text { Femoral Neck And Wrist }\end{array}$ \\
\hline $\begin{array}{l}\text { Study } \\
\text { group }\end{array}$ & Sex & $\begin{array}{l}\text { At the } \\
\text { beginning of } \\
\text { the study }\end{array}$ & $\begin{array}{l}\text { After } \\
\text { 6 months } \\
\text { fallow-up }\end{array}$ & $\begin{array}{l}\text { After } \\
\mathbf{2} \text { years fallow- } \\
\text { up }\end{array}$ \\
\hline Zol & Male & $<-1.7$ SD & $<-2$ SD & -2.5 SD \\
\hline
\end{tabular}




\begin{tabular}{|l|l|l|l|l|}
\hline $\begin{array}{l}\text { group- } \\
130 \\
\text { patients }\end{array}$ & Female & $<-1.5 \mathrm{SD}$ & $<-1.8 \mathrm{SD}$ & $-2 \mathrm{SD}$ \\
\hline $\begin{array}{l}\text { Placebo } \\
\text { group } \\
150 \\
\text { patients }\end{array}$ & Male & $<-1.7 \mathrm{SD}$ & $<-1.7 \mathrm{SD}$ & $<-1.5 \mathrm{SD}$ \\
\cline { 2 - 5 } & Female & $<-1.5 \mathrm{SD}$ & $<-1.5 \mathrm{SD}$ & $<-1.3 \mathrm{SD}$ \\
\hline
\end{tabular}

\section{DISCUSSION:}

Our study demonstrated that once yearly administration of Zoledronic acid significantly reduced the risk of fractures and increased BMD with a reduction in bone turn over in our patients with primary osteoporosis. Our study showed no apparent adverse events identified in previous clinical studies of ZOL. The efficacy of Zoledronic acid to reduce the risk of new fractures in patients with primary osteoporosis is similar to that seen in HORIZON-PFT study. The high incidence fractures in our study is due to increased fracture risks in our patients ${ }^{8}$. Mean BMD levels are low in our study compared to WHO definitions of levels of Bone Mineral Density as shown in the table no 2, due to ethnicity of patients.

\begin{tabular}{|l|l|}
\hline $\begin{array}{l}\text { Table-2: World Health Organisation definitions based on Bone } \\
\text { Mineral Density levels }\end{array}$ \\
\hline Level & Definition \\
\hline Normal & $\begin{array}{l}\text { BMD is within 1 SD }(+1 \text { or }-1) \text { of the young adult } \\
\text { mean }\end{array}$ \\
\hline Low BMD & $\begin{array}{l}\text { BMD is between } 1 \text { and } 2.5 \text { SD below the young } \\
\text { adult mean } 1(-1 \text { to }-2.5 \text { SD) }\end{array}$ \\
\hline Osteoporosis & $\begin{array}{l}\text { BMD is } 2.5 \text { SD or more below the young adult } \\
\text { mean }(-2.5 \text { SD or lower })\end{array}$ \\
\hline
\end{tabular}

Asian patients showed a higher incidence of fractures and the efficacy of ZOL to reduce the fracture risk is same among other ethnic groups?. The incidence osteoporotic fracture as defined by WHO was also significantly lower in the ZOL group than that in the placebo group. We have set the occurrence of new fractures as end point in our study. Within two years, the base line increase in BMD could not be assessed in all the patients at end of the study. The mean percent change from baseline spine, femoral neck BMD was significantly higher in the ZOL group than that in the placebo group in all assessment points in our study. The potency of once yearly administration of Zoledronic acid to reduce bone turnover and increase in BMD in our small population study is similar to the HORIZON-PET study. The adverse events shown in the other studies were not noticed in our study ${ }^{5}$. Most of the adverse events were due to acute phase reactions including pyrexia, myalgia and influenza like illness.

This is a small sample study, short duration and most of the patients were female, so it had some limitations. However this study demonstrated that once yearly administration Zoledronic acid significantly reduced the risk of new morphogenic fractures in postmenopausal women with primary osteoporosis. Based on the guide lines the nutritional intake of calcium is $800 \mathrm{mg}$ and vitamin-D is 400 $800 \mathrm{IU}$ in our study group, we found our patients are taking lower than the required daily dosages. Therefore the doses of calcium- $610 \mathrm{mg}$ and vitamin-D $400 \mathrm{IU}$ were considered enough to supplement the daily intake.

\section{CONCLUSION:}

Our study demonstrated the efficacy and safety of once yearly administration of Zoledronic acid $5 \mathrm{mg}$ in low compliance and rural areas of our country. The Zoledronic acid is beneficial for the prevention of fractures in osteoporotic patients and subsequent reduction of morbidity and mortality.

\section{REFERENCES:}

1. Russell RG, Xia Z, Dunford JE, Oppermann U, Kwaasi A, Hulley PA, Kavanagh KL, Triffitt JT, Lundy MW, Phipps RJ, Barnett BL, Coxon FP, Rogers MJ, Watts NB, Ebetino FH. Bisphosphonates: an update on mechanisms of action and how these relate to clinical efficacy. Ann N Y Acad Sci. 2007;1117:209-257.

2. Black DM, Delmas PD, Eastell R, Reid IR, Boonen S, Cauley JA, Cosman F, Lakatos P, Leung PC, Man Z, Mautalen C, Mesenbrink P, Hu H, Caminis J, Tong K, Rosario-Jansen T, Krasnow J, Hue TF, Sellmeyer D, Eriksen EF, Cummings SR. Once-yearly zoledronic acid for treatment of postmenopausal osteoporosis. N Engl J Med. 2007:356:1809-1822.

3. Reid DM, Devogelaer JP, Saag K, Roux C, Lau CS, Reginster JY, Papanastasiou P, Ferreira A, Hartl F, Fashola T, Mesenbrink P, Sambrook PN. Zoledronic acid and risedronate in the prevention and treatment of glucocorticoid-induced osteoporosis (HORIZON): a multicentre, double-blind, double-dummy, randomised controlled trial. Lancet. 2009;373:1253-1263.

4. Boonen S, Reginster JY, Kaufman JM, Lippuner K, Zanchetta J, Langdahl B, Rizzoli R, Lipschitz S, Dimai HP, Witvrouw R, Eriksen E, Brixen K, Russo L, Claessens F, Papanastasiou P, Antunez O, Su G, Bucci-Rechtweg C, Hruska J, Incera E, Vanderschueren D, Orwoll E. Fracture risk and zoledronic acid therapy in men with osteoporosis. N Engl J Med. 2012;367:1714-1723.

Lyles KW, Colón-Emeric CS, Magaziner JS, Adachi JD, Pieper CF, Mautalen C, Hyldstrup L, Recknor C, Nordsletten L, Moore KA, Lavecchia C, Zhang J, Mesenbrink P, Hodgson PK, Abrams K, Orloff JJ, Horowitz Z, Eriksen EF, Boonen S. Zoledronic acid and clinical fractures and mortality after hip fracture. N Engl J Med. 2007;357:1799-1809. doi: 10.1056/NEJMoa074941.

6. Kanis JA, on behalf of the World Health Organization Scientific Group (2007) Assessment of osteoporosis at the primary health-care level. WHO Collaborating Centre for Metabolic Bone Diseases, University of Sheffield

7. Matsumoto T, Hagino H, Shiraki M, Fukunaga M, Nakano T, Takaoka K, Morii H, Ohashi Y, Nakamura T. Effect of daily oral minodronate on vertebral fractures in Japanese postmenopausal women with established osteoporosis: a randomized placebocontrolled double-blind study. Osteoporosis Int. 2009;20:1429-1437.

8. Nakamura T, Sugimoto T, Nakano T, Kishimoto H, Ito M, Fukunaga M, Hagino H, Sone T, Yoshikawa H, Nishizawa Y, Fujita T, Shiraki M. Randomized Teriparatide [human parathyroid hormone (PTH) 1-34] once-weekly efficacy research (TOWER) trial for examining the reduction in new vertebral fractures in subjects with primary osteoporosis and high fracture risk. J Clin Endocrinol Metab. 2012;97:3097-3106.

9. Hwang JS, Chin LS, Chen JF, Yang TS, Chen PQ, Tsai KS, Leung PC. The effects of intravenous zoledronic acid in Chinese women with postmenopausal osteoporosis. J Bone Miner Metab. 2011;29:328-333.

10. Gehlbach S, Saag KG, Adachi JD, Hooven FH, Flahive J, Boonen S, Chapurlat RD, Compston JE, Cooper C, Díez-Perez A, Greenspan SL, LaCroix AZ, Netelenbos JC, Cor P. Lindsay R. Previous fractures at multiple sites increase the risk for subsequent fractures: the global longitudinal study of osteoporosis in women. J Bone Miner Res. 2012;27:645-653. 